and partial remission as more than $50 \%$ reduction in proteinuria to sub-nephrotic levels and serum creatinine within $10 \%$ from baseline.

Results: We have included 55 patients (80\% women) with biopsy-proven LN (age at biopsy $38 \pm 13$ years). On renal histology, one patient was class I LN, two patients were class II, 7 were class III, 5 were class III+V, 23 were class IV, two were class IV+V, 11 class $\mathrm{VI}$ and 4 had other features. Median baseline NLR was 3.64 (IQR: 1.85, 6.93), PLR was 167 (IQR: 116, $300)$ and MPV was 10.0 (IQR: 9.2, 10.8). There were no differences in any of the three parameters between different classess of LN (all $p>0.05$ ). Eighteen patients achieved complete remission (CR), 16 partial remission and 21 did not achieve remission. None progressed to ESRD and two patients died, both from sepsis. There no differences in NLR, PLR and MPV at the time of biopsy between group which achieved CR/PR vs. no remission (all $p>0.05$; Figure 1). We constructed a thorough multivariate regression model which showed that neither NLR, PLR or MPV are predictors of renal remission in LN.

Conclusion: NLR, PLR and MPV are not useful prognostic markers in predicting renal remission in LN.

REFERENCES:

[1] Hartmann LT, et al. Open Rheumatol J. 2018 Aug 31;12:129-138.

[2] Chen SY, et al. J Res Med Sci. 2018 May 30;23:48.

[3] Zhao CN, et al. Rheumatol Int. 2018 Sep;38(9):1635-1641.
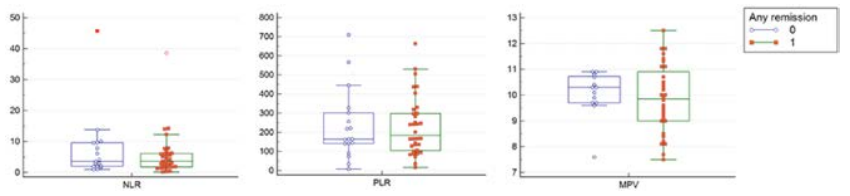

Disclosure of Interests: None declared

DOI: 10.1136/annrheumdis-2021-eular.4164

\section{AB0350 MATERNAL AND FETAL OUTCOME IN MEXICAN WOMEN WITH PRIMARY ANTIPHOSPHOLIPID SYNDROME, SECONDARY ANTIPHOSPHOLIPID SYNDROME AND SYSTEMIC LUPUS ERYTHEMATOSUS WITH ANTIPHOSPHOLIPID ANTIBODIES}

A. A. Sánchez ${ }^{1}$, D. Miranda ${ }^{1}$, M. A. Saavedra ${ }^{1}$, A. Sanchez Gonzalez ${ }^{1}$, Z. Castro ${ }^{1}{ }^{1}$ Hospital de Especialidades La Raza, Rheumatology, Ciudad de México, Mexico

Background: Primary antiphospholipid syndrome (APS) is associated with a higher frequency of maternal-fetal adverse outcomes, with increased risk when APS is associated with systemic lupus erythematosus (SLE).

Objectives: We compared maternal-fetal complications in patients with primary APS, APS associated with SLE and SLE with anti-phospholipid antibodies (aPLs).

Methods: Observational, analytical, retrospective, cross-sectional, comparative study, between 2009-2019. Three groups were compared: primary APS, APS associated with SLE and SLE with anti-phospholipid antibodies (aPLs).

Results: We include 179 pregnant women, $31.8 \%$ with primary APS, $35.8 \%$ with APS associated with SLE, and $32.4 \%$ with SLE and aPLs A history of a higher frequency of abortions was found in APS associated with SLE $(62.5 \%, p<0.001)$ and thrombosis $(61.9 \%, p<0.001)$ and $\mathrm{aCL} \operatorname{lgG}+$ in primary APS $(80.7 \%$, $p=0.011$ ). More frequent use during pregnancy of antimalarials is applied in associated APS $(81.30 \%, p<0.001)$ and aspirin / heparin in primary APS $(96.5 \%$ / $94.7 \%, \mathrm{p}<0.001)$. Abortions were observed more frequently in APS associated with SLE $(23.80 \%, \mathrm{p}=0.021)$ and preeclampsia / HELLP in primary APS $(31.6 \%$ and $15.8 \%, p=0.047)$ who were also less frequently the use of antimalarial ( $24 \%$ vs. $81.3 \%$ vs. $72.4 \%$, p <0.001) compared to the other groups. Table 1 Conclusion: Patients with APS and SLE have an increased risk of miscarriage whereas those with primary APS have an increased risk for preeclampsia / HELLP. The use of antimalarials could reduce the risk of hypertensive disorders of pregnancy.

REFERENCES:

[1] Schreiber K, Sciascia S, de Groot PG, et al. Antiphospholipid syndrome. Nat Rev Dis Primers 2018:4:17103.

[2] De Carolis S, Tabacco S, Rizzo F, et al. Antiphospholipid syndrome: An update on risk factors for pregnancy outcome. Autoimmun Rev. 2018;17: 956-66.
Table 1. Comparison between groups of adverse maternal-fetal outcome.

\begin{tabular}{|c|c|c|c|c|}
\hline & $\begin{array}{c}\text { Secondary } \\
\text { antiphospho- } \\
\text { lipid syndrome } \\
(n=64)\end{array}$ & $\begin{array}{c}\text { Primary } \\
\text { antiphospho- } \\
\text { lipid syndrome } \\
\quad(n=57)\end{array}$ & $\begin{array}{l}\text { Systemic lupus } \\
\text { erythematosus with } \\
\text { antiphospholipid } \\
\text { antibodies }(n=58)\end{array}$ & $\mathbf{P}$ \\
\hline Fetal complications & $48(76.20 \%)$ & $43(75.40 \%)$ & $31(56.40 \%)$ & 0.034 \\
\hline Growth restriction & $9(14.30 \%)$ & $8(14 \%)$ & $7(12.50 \%)$ & 0.955 \\
\hline Oligohydramnios & $6(9.50 \%)$ & $5(8.80 \%)$ & $5(8.90 \%)$ & 0.989 \\
\hline Prematurity & $23(52.30 \%)$ & $25(56.80 \%)$ & $19(42.20 \%)$ & 0.37 \\
\hline Abortion & 15 (23.80\%) & $3(5.40 \%)$ & $9(16.10 \%)$ & 0.021 \\
\hline Stillbirth & $7(11.10 \%)$ & $10(17.90 \%)$ & $5(9.10 \%)$ & 0.343 \\
\hline Low birth weight & $20(52.60 \%)$ & $21(48.80 \%)$ & $15(37.50 \%)$ & 0.373 \\
\hline Malformations & $5(8.10 \%)$ & $0(0 \%)$ & $0(0 \%)$ & 0.01 \\
\hline Maternal complications & $40(63.50 \%)$ & $25(43.90 \%)$ & $21(36.80 \%)$ & 0.01 \\
\hline Pre-eclampsia. & $15(23.80 \%)$ & $18(31.60 \%)$ & $7(12.30 \%)$ & 0.046 \\
\hline HELLP & $4(6.30 \%)$ & $9(15.8 \%)$ & $2(3.50 \%)$ & 0.047 \\
\hline $\begin{array}{l}\text { Premature rupture of } \\
\text { membranas }\end{array}$ & $7(11.10 \%)$ & $5(8.8 \%)$ & $4(7.10 \%)$ & 0.75 \\
\hline Maternal death & $1(1.60 \%)$ & $0(0 \%)$ & $1(1.80 \%)$ & 0.616 \\
\hline
\end{tabular}

Disclosure of Interests: None declared

DOI: 10.1136/annrheumdis-2021-eular.4187

\begin{tabular}{|l}
\hline AB0351 \\
PROGRESSION TO SEVERE LUPUS NEPHRITIS \\
IN PATIENTS WITH SYSTEMIC LUPUS \\
ERYTHEMATOUS: UPDATE FROM A COLOMBIAN \\
COHORT
\end{tabular}

S. Herrera ${ }^{1}$, J. Marenco Maldonado ${ }^{1}$, J. C. Diaz-Coronado ${ }^{1,2}$, D. RojasGualdrón ${ }^{3}$, D. Hernandez-Parra ${ }^{1}$, R. Pineda.Tamayo ${ }^{1} .{ }^{1}$ Artmedica IPS, Clinical Information Group, Medellín, Colombia; ${ }^{2}$ CES University, Department of Internal Medicine, Medellín, Colombia; ${ }^{3}$ CES University, Facultad de medicina, Medellín, Colombia

Background: Continuous monitoring of patients with Systemic lupus erythematosus (SLE) provides relevant information

Objectives: To update the analysis of clinical and immunological characteristics associated with time to severe renal involvement in patients with Systemic Lupus Erythematous in a Colombian cohort followed from January 2015 to October 2020

Methods: A retrospective follow-up study based on clinical records. Patients with SLE diagnosis fulfilled either 1987 American College of Rheumatology Classification Criteria for SLE or 2011 Systemic Lupus International Collaborating Clinics (SLICC) classification criteria for SLE. We included patients with the diagnosis of lupus nephritis according to Wallace and Dubois criteria Patients who did not have at least two follow-up measurements or had a cause of nephritis other than lupus were excluded. The primary outcome was defined as the time from diagnosis to severe renal involvement defined as creatinine clearance $\leq 50 \mathrm{ml} / \mathrm{min}$, 24-hour proteinuria $\geq 3.5$ grams o end-stage renal disease. Updated age and sex-adjusted survival functions and Hazard ratios (HR) with $95 \%$ confidence intervals and $p$-values were estimated using parametric Weibull models for interval-censored data. $P$ values $<0.05$ were considered statistically significant. Descriptive statistics were previously reported in EULAR 2020 (1)

Results: 548 patients were analyzed: 67 were left-censored as they presented renal involvement at entry, 25 were interval censored as outcome occurred between study visits ( 19 new events), and 456 were right-censored as involvement was not registered during follow-up. In this cohort update Age and sex-adjusted Hazard Ratios for high blood pressure were $\mathrm{HR}=3.1(95 \% \mathrm{Cl} 1.5-6.3$; $\mathrm{p}$-value $=0.003)$ and Anti-RO (per unit increase) $\mathrm{HR}=1.003(95 \% \mathrm{Cl} 1.001-1.005$ $\mathrm{p}$-value $=0.029)$. Figure 1 shows the updated age and sex-adjusted survival function

Conclusion: In this cohort update, we found similar clinical and immunological characteristics associated with time to severe renal involvement in SLE patients to those reported in (1). However, continuous follow-up allows us to deepen our understanding of the progression to severe renal involvement in SLE patients

REFERENCES:

[1] Herrera S, Diaz-Coronado JC, Rojas-Gualdrón D, Betancur-Vasquez L, Gonzalez-Hurtado D, Gonzalez-Arango J, et al. SAT0210 factors associated with time to severe lupus nephritis in a cohort of colombian patients. Ann Rheum Dis. junio de 2020;79(Suppl 1):1048.21048 